\title{
A highly sensitive immunoassay for the detection of prion infected material in whole human blood without the use of Proteinase $\mathrm{K}$.
}

M. Howard Tattum ${ }^{1}$, Samantha Jones ${ }^{1}$, Suvankar Pal ${ }^{2}$, Azedeh Kahlili-Shirazi ${ }^{1}$, John Collinge $^{1}$ and Graham S. Jackson ${ }^{1 *}$

${ }^{1}$ MRC Prion Unit and Department of Neurodegenerative Disease, Institute of Neurology, University College London, Queen's Square, London, WC1N 3BG, UK.

${ }^{2}$ Current address: Department of Neurology, Western General Hospital, Crewe Road, Edinburgh, EH4 2XU.

*To whom correspondence should be addressed

Tel: (+44) 02076762190

Fax: (+44) 02076762180

E-mail: g.s.jackson@prion.ucl.ac.uk

This work was supported by the UK Medical Research Council

The authors declare that they have a conflict of interest relevant to the manuscript submitted to TRANSFUSION. J.C. is a Director and J.C. and G.S.J are shareholders and consultants for D-Gen Limited (London), an academic spin-out company which produces and markets the antibodies used in the Immunoassay experiments described in this manuscript.

Running Head: Detection of abnormal PrP in whole human blood 


\section{Abstract}

\section{Background}

The causal association of variant Creutzfeldt-Jakob disease (vCJD) with Bovine Spongiform Encephalopathy (BSE) has raised significant concerns for public health. Assays for vCJD infection are vital for the application of therapeutics, the screening of organ donations and to maintain a safe blood supply. Currently the best diagnostic tools for $\mathrm{VCJD}$ depend upon the detection of disease associated prion protein $\left(\mathrm{PrP}^{\mathrm{Sc}}\right)$ which is distinguished from normal background $\operatorname{PrP}\left(\operatorname{PrP}^{\mathrm{C}}\right)$ by proteinase $\mathrm{K}$ digestion which can also degrade up to $90 \%$ of the target antigen.

\section{Study Design and Methods}

A sandwich ELISA methodology was developed using unique antibodies for the detection of disease associated $\mathrm{PrP}$ in the absence of proteinase $\mathrm{K}$ pre-treatment. In combination with immunoprecipitation the assay was optimised for the detection of pathogenic PrP in large volumes of whole blood.

\section{Results}

Optimisation of the assay allowed detection of $2 \times 10^{4} \mathrm{LD}_{50}$ Units $\mathrm{ml}^{-1}$ spiked in whole blood. Application of the assay to clinically relevant volumes enabled the detection of $750 \mathrm{LD}_{50}$ Units $\mathrm{ml}^{-1}$ in $8 \mathrm{ml}$ of whole blood.

\section{Conclusion}


By combining the use of a unique antibody which selectively immunoprecipitates $\operatorname{PrP}^{\mathrm{Sc}}$ with glycoform restrictive antibodies we have developed a rapid assay for vCJD infection that does not require any PK pre-treatment to achieve high levels of specificity in whole human blood, the most challenging potential analyte. The sensitivity of detection of vCJD infection is greater than the equivalent of a $>2.5$ million-fold dilution of infected brain, providing a highly sensitive immunoassay compatible with blood screening.

Keywords: Variant CJD, Prion, PrP, Immunoassay 


\section{Introduction}

Prion diseases are a group of fatal, infectious neurodegenerative diseases, which included bovine spongiform encephalopathy (BSE) in cattle, scrapie in sheep and CreutzfeldtJakob disease (CJD) in humans ${ }^{1,2}$. Classically, the crucial step in the transmission and propagation of prion diseases, according to the protein-only hypothesis ${ }^{3}$ is the conversion of the host's normal, cellular form of the prion protein $\left(\operatorname{PrP}^{\mathrm{C}}\right)$, via a post-translational process to a protease resistant, aggregated form $\left(\mathrm{PrP}^{\mathrm{Sc}}\right)^{4}$. Detection of disease-associated, abnormal forms of the prion protein such as $\operatorname{PrP}^{\mathrm{Sc}}$ is the most widely used and specific criterion for the diagnosis of prion disease in humans and animals ${ }^{1,2}$.

Historically, methods to detect and diagnose prion disease have required post-mortem examination of tissue and according to the World Health Organisation (WHO) diagnostic criteria for variant CJD (vCJD), disease can only be classified as 'probable' in the presence of significant neurological deficit and confirmed as definite by means of neuropathological examination using immunohistochemical staining ${ }^{5}$. Despite this the use of highly sensitive western blotting has allowed the analysis of the pattern of deposition of $\operatorname{PrP}^{\mathrm{Sc}}$ in a wide variety of tissues from vCJD patients ${ }^{6}$ including tonsil tissue

obtained at post-mortem and biopsy ${ }^{7}$. The use of tonsil biopsy to determine if $\mathrm{PrP}^{\mathrm{Sc}}$ is present by western blotting coupled with immunohistochemistry has proved both sensitive and specific for $\mathrm{vCJD}^{8}$ and allows patient care plans to be established, patients and families to be counselled accordingly and appropriate infection control measures implemented $^{9,10}$, albeit at a late stage in disease progression. 
The pre-clinical phase of VCJD is currently unidentifiable, ranging from years to several decades, and presents a substantial infection risk to others via blood transfusion products, tissue and organ transplantation and other iatrogenic routes such as medical and dental procedures with contaminated instruments. Indeed blood transfusions have been shown to be an effective route of infection for BSE and scrapie in sheep ${ }^{11}$ and VCJD in humans ${ }^{12-14}$. The introduction of a sensitive and specific blood based molecular diagnostic test for prion disease will provide an immediate solution to all of these problems and will facilitate early disease diagnosis and entry into therapeutic trials. However, the detection of $\operatorname{PrP}^{\mathrm{Sc}}$ in blood is considerably more challenging than in other tissues.

Very little is known about the nature and distribution of abnormal PrP in blood. Estimates of titres vary widely but the levels of prion infectivity demonstrated in buffy coat fractions as well as plasma derived from rodent sources are low ${ }^{15}$, with as little as 10 $\mathrm{LD}_{50}$ Units present in $1 \mathrm{ml}$ of whole blood. In addition to the extremely low concentration of disease associated $\operatorname{PrP}$, the $\operatorname{PrP}^{\mathrm{C}}$ background is very high. There is a dearth of information available about the biochemical nature of disease associated $\operatorname{PrP}$ in blood, in particular uncertainty remains about whether pathogenic $\mathrm{PrP}$ in blood is protease resistant. Evidence is accumulating that challenges the belief that all forms of diseaseassociated $\operatorname{PrP}$ are resistant to proteolysis. Indeed, it has recently been shown that the majority of disease associated PrP may well be sensitive to proteolytic digestion with proteinase $\mathrm{K}(\mathrm{PK})^{16-21}$. Therefore any blood based assay for disease-associated PrP must 
not only have high sensitivity but also be extremely specific for abnormal PrP against a large background excess of $\operatorname{PrP}^{\mathrm{C}}$.

Over the last decade several groups have developed a range of different approaches to the problem of blood-based diagnosis of prion diseases. Protein Misfolding Cyclic Amplification (PMCA) is a technique which can amplify minute quantities of $\mathrm{PrP}^{\mathrm{Sc}}$ to levels which can be detected by conventional methods ${ }^{22}$ such as western blotting or immunoassays (Enzyme-Linked ImmunoSorbent Assays (ELISA) or ConformationDependent Immunoassay $\left.(\mathrm{CDI})^{16}\right)$. PMCA has been used to detect $\mathrm{PrP}^{\mathrm{Sc}}$ in buffy coat fractions of rodent blood ${ }^{23,24}$. More recently, PK resistant $\operatorname{PrP}\left(\mathrm{PrP}^{\mathrm{RES}}\right)$ was amplified from blood leukocyte preparations obtained from scrapie-infected sheep ${ }^{25}$. Human platelet homogenates have been used in PMCA experiments as an alternative substrate to amplify $\operatorname{PrP}^{\mathrm{Sc}}$ from variant and sporadic CJD brain homogenates ${ }^{26,27}$. Serial PMCA gave a 10,000 fold increase in sensitivity, resulting in the detection of $10 \mathrm{ng}$ of vCJD brain in a $100 \mu \mathrm{l}$ PMCA reaction ${ }^{27}$. However, the authors report an acute compatibility issue between the seed/substrate PRNP condon 129 which remains to be overcome. The technical limitations associated with PMCA, such as the timescales involved, substrate availability and suitability and increasing evidence for the spontaneous generation of protease resistant $\operatorname{PrP}$ de novo ${ }^{25,28}$ mean that PMCA is unlikely to provide the sole technology for a prion blood screening assay. A modified PMCA approach using recombinant $\mathrm{PrP}$ as the substrate with agitation instead of sonication has been used to distinguish between normal and prion-infected cerebral spinal fluid (CSF) obtained from experimentally infected hamsters ${ }^{29}$. Other approaches have included the use of ligands 
which specifically capture disease-associated $\mathrm{PrP}^{\mathrm{Sc}}$ from blood fractions, thereby concentrating the aberrant PrP before detection by standard methods ${ }^{30-32}$. Immunoassays specific for aggregated PrP, which increase sensitivity by linking signal amplification with target amplification using a simplified PMCA like reaction, have also been developed $^{33}$

We have determined to develop an immunoassay for disease-associated PrP that does not require depletion of $\operatorname{PrP}^{\mathrm{C}}$ by proteolysis with proteinase $\mathrm{K}$ and that can be applied to whole blood. Here, we report the development of a highly sensitive and selective assay for the detection of disease associated $\mathrm{PrP}^{\mathrm{Sc}}$ from clinically relevant volumes of whole blood without the need for PK digestion. We have screened a range of monoclonal antibodies that have been raised against recombinant $\operatorname{PrP}$ in $\operatorname{PrP}^{0 / 0}$ knockout mice ${ }^{34}$ for their effectiveness to distinguish between $\operatorname{PrP}^{\mathrm{Sc}}$ and $\operatorname{PrP}^{\mathrm{C}}$ in the absence of $\mathrm{PK}$ treatment in a sandwich ELISA format. Optimisation of the assay allowed the detection of disease associated, PK-resistant and sensitive PrP spiked into whole blood at the picogram level. Coupling of the sandwich ELISA to the selective immunoprecipitation of $\operatorname{PrP}^{\mathrm{Sc}}$ by a novel monoclonal antibody (ICSM 33) which has selectivity for disease-associated isoforms of PrP from large volumes of whole blood (Jackson et al, Manuscript submitted) allowed the detection of vCJD brain homogenate spiked into whole human blood at a dilution of $>2.5$ million fold of total brain. 


\section{Materials and Methods}

\section{Tissues samples}

Storage and biochemical analysis of human brain samples was performed with consent from relatives and with approval from the Local Research Ethics Committee of the Institute of Neurology/National Hospital for Neurology and Neurosurgery (London, U.K.). All procedures were carried out in a microbiological containment level III facility with strict adherence to safety protocols. Brain homogenates $(10 \% \mathrm{w} / \mathrm{v})$ from patients with neuropathologically confirmed vCJD and normal control brain homogenates were prepared in Dulbecco's PBS (DPBS) lacking $\mathrm{Ca}^{2+}$ or $\mathrm{Mg}^{2+}$ ions by serial passage through needles of decreasing diameter or the use of tissue grinders (Anachem) ${ }^{6,35}$. Normal brains from the outbred CD1 strain of wild-type mice, as well as brains from CD1 mice which were experimentally infected with the Rocky Mountain Laboratory (RML) strain of prions $^{36}$, a mouse adapted prion strain isolated by serial passage from an original inoculum of sheep scrapie, were homogenized in DPBS lacking $\mathrm{Ca}^{2+}$ or $\mathrm{Mg}^{2+}$ ions by the use of tissue grinders (Anachem) to give a final concentration of $10 \%(\mathrm{w} / \mathrm{v})$. Tissue homogenates were stored as aliquots in eppenforf tubes at $-80^{\circ} \mathrm{C}$. Whole human blood was obtained from the National Blood service, UK.

For clarity, all dilutions of infectious material will be quoted as the fold dilution of total brain or the concentration of infectious titre $\left(\mathrm{LD}_{50}\right.$ Unit $\left.\mathrm{ml}^{-1}\right)$. The intracerebral infectious prion titre of the $10 \%(\mathrm{w} / \mathrm{v})$ RML brain homogenate used was determined to be $10^{8.3} \mathrm{LD}_{50}$ Units $\mathrm{ml}^{-1}$ by serial dilution and bioassay ${ }^{21}$. The precise infectious titre of vCJD brain is unknown. Therefore we have made the assumption that vCJD has a similar 
prion titre to RML and have calculated dilutions accordingly. The quantity of $\operatorname{PrP}^{\mathrm{Sc}}$ found in terminal prion disease brain has been calculated as $7 \mu \mathrm{g}$ of $\mathrm{PrP}^{\mathrm{Sc}}$ per gram wet weight brain $^{37}$ and we have used this estimation for all subsequent calculations.

\section{Screening for optimal monoclonal antibody pairs in sandwich ELISA}

CD1 and RML-infected brain homogenates were processed with or without Proteinase K digestion and in native and denatured conditions. Briefly, $10 \mu 1$ aliquots of $10 \%(\mathrm{w} / \mathrm{v})$ brain homogenate were treated with $1 \mu \mathrm{l}$ of Benzonase (25 U/ $\mu 1$, Merck) for 10 minutes at $37^{\circ} \mathrm{C}$ with agitation at $750 \mathrm{rpm}$ in a Thermomixer (Eppendorf). PK digested samples were incubated at $100 \mu \mathrm{g} / \mathrm{ml}$ final concentration for 10 minutes at $55^{\circ} \mathrm{C} .2 \mu 1$ of $500 \mathrm{mM}$ AEBSF (4-(2-Aminoethyl) benzenesulphonyl fluoride hydrochloride) were added to all samples. For denatured samples, $10 \mu \mathrm{l}$ of $2 \%(\mathrm{w} / \mathrm{v})$ sodium dodecyl sulphate (SDS) was added and samples heated for 10 minutes at $100^{\circ} \mathrm{C}$. All samples were adjusted to $600 \mu \mathrm{l}$ with IP buffer $(50 \mathrm{mM}$ Tris/HCl, pH8.4, containing 2\% v/v Triton X-100 (molecular biology grade, Sigma), 2\% w/v sodium lauroylsarcosine (Calbiochem) and 2\% w/v bovine serum albumin (Fraction V, protease free, Sigma-Aldrich)). Aliquots were transferred to high binding capacity microtitre plates (Microlon 96W, Greiner Bio-One) coated with $250 \mathrm{ng} /$ well of immobilized anti-PrP monoclonal capture antibodies (ICSM $3,4,6,7,10,15,19,24,26,33,37,38,41$ and 42; D-Gen Ltd, London). After incubation at $37^{\circ} \mathrm{C}$ for 1 hour with constant agitation, wells were washed with $3 \times 300 \mu 1$ of PBST (Phosphate Buffered Saline containing 0.05\% Tween 20 (Sigma)) using an automated microplate washer and $100 \mu \mathrm{l}$ of PBS containing $1 \% \mathrm{v} / \mathrm{v}$ Tween-20 and $1 \mu \mathrm{l} / \mathrm{ml}$ biotinylated anti-PrP monoclonal detection antibody ICSM 18 or 35 (D-Gen Ltd, 
London) added. After 1 hour at $37^{\circ} \mathrm{C}$ with constant agitation, wells were washed as detailed above and $100 \mu \mathrm{l}$ of PBS containing $1 \% \mathrm{v} / \mathrm{v}$ Tween-20 and a 1:10,000 dilution of streptavidin-horseradish-peroxidase conjugate (Dako Cytomation) added. After incubation at $37^{\circ} \mathrm{C}$ for $30 \mathrm{~min}$ with constant agitation, wells were washed with $4 \times 300 \mu 1$

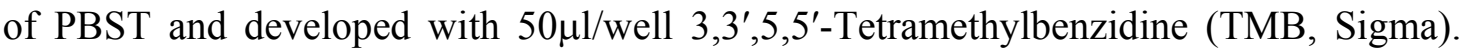
The colorimetric reaction was stopped with addition of $50 \mu \mathrm{l} /$ well $2 \mathrm{M}$ Hydrochloric Acid and absorbance measured at $450 \mathrm{~nm}$ in a Tecan SpectraFluor microplate reader.

\section{Optimised high sensitivity ICSM10 sandwich ELISA without PK digestion}

$10 \mu \mathrm{l}$ samples were treated with $1 \mu \mathrm{l}$ of Benzonase $(25 \mathrm{U} / \mu \mathrm{l}$, Merck) followed by Thermolysin digestion $(10 \mu \mathrm{g} / \mathrm{ml}$ final concentration, $\mathrm{BDH})$ at $50^{\circ} \mathrm{C}$ for 10 minutes with constant agitation and subsequent addition of $20 \mu$ l of Denaturation buffer (6M Guanidine Hydrochloride ( $\mathrm{GdHCl}$ ) in PBS containing 10mM EDTA and 1x Complete protease inhibitor cocktail (Roche)). Following incubation at room temperature for 10 minutes IP buffer is added to a final volume of $200 \mu$ l. Aliquots were transferred to high binding, black microtitre plates (Microlon 96W, Greiner Bio-One) containing immobilized ICSM10 (250ng/well). Wells were washed and processed as described above. Biotinylated ICSM35 was used as the detection antibody. Wells were developed with $100 \mu 1$ of QuantaBlu Fluorogenic Peroxidase Substrate (Pierce). Fluorescence $\left(\lambda_{\mathrm{ex}}=325 \mathrm{~nm}, \lambda_{\mathrm{em}}=425 \mathrm{~nm}\right)$ was measured on a Tecan SpectraFluoro microplate reader.

Immunoprecipitation and detection by high sensitivity ELISA of disease-associated prion protein from whole blood spiked with vCJD brain homogenate 
Whole blood $(250 \mu \mathrm{l})$ was spiked with vCJD brain homogenate dilutions. Equal volumes of $2 \times$ concentration of IP buffer were added along with $25 \mu 1$ of ICSM33 conjugated magnetic beads (Talon Dyna beads, Invitrogen) and incubated overnight at $4{ }^{\circ} \mathrm{C}$ in a rotator. Beads were washed $4 \times 1 \mathrm{ml}$ with IP buffer, $4 \times 1 \mathrm{ml}$ PBS containing $2 \% \mathrm{v} / \mathrm{v}$ Tween-20 and 2\% w/v NP40 and a final wash of $1 \mathrm{ml}$ PBS. Beads were resuspended in $10 \mu 1$ of PBS containing $10 \mu \mathrm{g} / \mathrm{ml}$ Thermolysin and incubated at $50^{\circ} \mathrm{C}$ for 10 minutes. 20 $\mu 1$ of Denaturation buffer was added and following incubation at room temperature for 10 minutes volumes were made up to $200 \mu \mathrm{l}$ with IP buffer and analysed by ICSM10 sandwich ELISA.

For $8 \mathrm{ml}$ whole blood samples, $8 \mathrm{ml}$ of $2 \mathrm{x}$ concentration IP buffer was added followed by Benzonase pre-treatment. Samples were divided into $1 \mathrm{ml}$ aliquots, ICSM33 coated magnetic beads added and incubated over night at $4^{\circ} \mathrm{C}$ in a rotator. Beads were washed as described above, before being pooled for Thermolysin digestion and preparation for ELISA in a minimum volume. 


\section{Results}

\section{Screen for monoclonal capture antibodies which discriminate between $\operatorname{PrP}^{S c}$ and $\operatorname{PrP}^{C}$ in the absence of Proteinase K digestion.}

Brain homogenates from normal CD1 and RML infected CD1 mice, processed for ELISA analysis with and without PK digestion and in a native or SDS denatured state, were used to screen our library of anti-PrP monoclonal antibodies for capture antibodies which show increased binding affinity for $\operatorname{PrP}^{\mathrm{Sc}}$ over $\operatorname{PrP}^{\mathrm{C}}$. Biotinylated ICSM18 and 35 (ICSM18B and ICSM35B) were tested as detection antibodies (data not shown). Several antibodies were determined to have selectivity in their binding of $\operatorname{PrP}^{\mathrm{Sc}}$ to $\operatorname{PrP}^{\mathrm{C}}$ independent of PK digestion. However, ICSM10, used as the capture antibody in combination with the detection antibody ICSM35B provided the greatest discrimination between prion infected and uninfected brain homogenates following denaturation (Figure 1). PK digestion reduced the detectable signal from RML homogenates by up to $58 \%$, a finding consistent with recent reported loses of signal following PK digestion ${ }^{21}$. ICSM10 capture and ICSM35B detection sandwich ELISA was therefore chosen for further development and adaption to a blood based assay.

\section{Optimisation of ICSM 10 sandwich ELISA}

Optimisation of sensitivity is essential if the assay is to approach the required limits of detection for the discrimination of endogenous prion infected blood from normal samples. Switching to a fluorometric detection system gave a four fold increase in sensitivity, from $2 \times 10^{6} \mathrm{ID}_{50}$ Units $\mathrm{ml}^{-1}$ to $5 \times 10^{5} \mathrm{ID}_{50}$ Units $\mathrm{ml}^{-1}$ at a threshold of 3 standard deviations above the CD1 controls (data not shown). 
A further limiting factor in assaying for low abundance targets is the quantity of sample that can be analysed at any one time. In this case the large volume of IP buffer required to dilute the SDS denaturant to a concentration below which it does not affect the antibody/antigen interaction was limiting. We therefore explored the use of Guanidine Hydrocholoride as a denaturant. Using increasing concentrations of $\mathrm{GdHCl}$, with subsequent dilution with a volume of IP buffer equivalent to that for SDS samples we established that a concentration of $4 \mathrm{M} \mathrm{GdHCl}$ was sufficient to produce a positive signal comparable to that previously obtained (Figure 2a). Optimisation for denaturant dilution to prevent inhibition of the antigen/antibody interaction whilst maximising the quantity of antigen per well was performed (Figure 2b). A final concentration of $0.4 \mathrm{M} \mathrm{GdHCl}$ (in $200 \mu \mathrm{l})$ proved optimal, resulting in a 3 fold increase in the RML to CD1 background signal ratio giving a 5 fold total increase in maximal signal over SDS denatured samples.

\section{Thermolysin pretreatment}

Thermolysin has recently been shown to completely digest $\operatorname{PrP}^{\mathrm{C}}$ in brain homogenates ${ }^{21,38}$ whilst leaving both PK-resistant and PK-sensitive forms of $\mathrm{PrP}^{\mathrm{Sc}}$ intact. Consequently we examined Thermolysin digestion as a means to further reduce assay background while minimizing the digestion of protease sensitive forms of disease associated PrP. Digestion with Thermolysin at a concentration of $10 \mu \mathrm{g} / \mathrm{ml}$ for 10 minutes at $50^{\circ} \mathrm{C}$ give a marginal increase in assay sensitivity from $2.5 \times 10^{5} \mathrm{ID}_{50}$ Units $\mathrm{ml}^{-1}$ equivalents per well to $1.25 \times 10^{5} \mathrm{ID}_{50}$ Units $\mathrm{ml}^{-1}$ (Figures $2 \mathrm{C} \& 2 \mathrm{D}$ ). In additional Thermolysin treatment significantly improved assay reliability and dose responses, 
facilitating the detection of less than $5 \mathrm{pg}$ of $\mathrm{PrP}^{\mathrm{Sc}}$ per well. These results were confirmed for vCJD by analysis of dilution series of vCJD brain homogenate (data not shown).

\section{Sensitivity of detection of vCJD spiked into whole blood}

Detection of $\operatorname{PrP}^{\mathrm{Sc}}$ in whole blood poses a far more difficult challenge than detection from brain homogenate or clarified blood fractions. However, whole blood has the advantage that it contains the total infectivity present within a sample. Currently the most sensitive and commonly used method for the detection of $\operatorname{PrP}^{\mathrm{Sc}}$ and the clinical diagnosis of $\mathrm{VCJD}$ is the selective precipitation of $\operatorname{PrP}^{\mathrm{Sc}}$ with sodium phosphotungstic acid followed by PK digestion and western blotting which can reliable detect 4,000 $\mathrm{LD}_{50}$ Units $\mathrm{ml}^{-1}$, equivalent to a 50,000 fold dilution of whole brain ${ }^{6}$. Serial dilution of vCJD brain homogenate into normal brain homogenate followed by spiking into whole human blood was used to determine the assay's sensitivity (Figure 3). Our optimised sandwich ELISA was shown to be able to detect $\mathrm{PrP}^{\mathrm{Sc}}$ at a dilution of $2 \times 10^{4} \mathrm{LD}_{50}$ Units $\mathrm{ml}^{-1}$ $\left(\sim 700 \mathrm{fg} \mathrm{PrP}^{\mathrm{Sc}}\right)$ in a total volume of $10 \mu 1$ of whole blood.

\section{Immunoprecipitation and detection of vCJD spiked into whole blood}

To improve the sensitivity of our immunoassay for prion infection and approach detection at the concentrations of $10-100 \mathrm{LD}_{50}{\mathrm{Units} \mathrm{ml}^{-1} \text { found in blood }}^{39}$ we require the ability to capture and enrich $\operatorname{PrP}^{\mathrm{Sc}}$ from large volumes of whole blood, maximising the amount of antigen per tissue sample that is applied to the ELISA. Hence we have studied the possibility of coupling an immunoprecipitation (IP) step with our discriminatory, high sensitivity ELISA as outlined in Figure 4. 
Characterization of the interactions of a particular antibody, ICSM33, with both $\operatorname{PrP}^{\mathrm{C}}$ and $\mathrm{PrP}^{\mathrm{Sc}}$ have previously shown that the aggregated nature of $\mathrm{PrP}^{\mathrm{Sc}}$ and other forms of abnormal $\operatorname{PrP}$ permit their isolation from $\operatorname{PrP}^{\mathrm{C}}$ by immunoprecipitation involving multivalent interactions (Jackson et al, Manuscript Submitted). Immunoprecipitation reactions with ICSM33 from $250 \mu 1$ of whole blood spiked with $10 \% \mathrm{w} / \mathrm{v}$ vCJD brain homogenate were performed as a dilution series. After Thermolysin digestion in situ, antigen was denatured and released from the beads by incubation in $4 \mathrm{M} \mathrm{GdHCl}$ before detection by the sandwich ELISA (Figure 5A). The combined methodology could reliably detect $3,200 \mathrm{LD}_{50}$ Units $\mathrm{ml}^{-1}$ in $250 \mu 1$ of whole blood, equivalent of $\sim 2.8 \mathrm{pg}$ of $\operatorname{PrP}^{\mathrm{Sc}}$ per assay well at a dilution of 150,000 fold.

Due to the particularly low levels of $\mathrm{PrP}^{\mathrm{Sc}}$ present in blood it is likely the assay would require the enrichment of $\mathrm{PrP}^{\mathrm{Sc}}$ from larger, clinically accessible volumes of whole blood. To investigate the adaption of our assay to larger blood volumes we performed ICSM33 immunoprecipitation reactions on volumes up to $8 \mathrm{ml}$ of whole blood spiked with either normal or vCJD brain homogenate before detection in our sandwich ELISA (Figure 5B). The coupled assay was clearly able to distinguish between vCJD and normal spiked samples with a detection sensitivity of $21 \mathrm{pg}$ of $\mathrm{PrP}^{\mathrm{Sc}}$ in $8 \mathrm{mls}$ of whole blood, corresponding to detection at a concentration of $750 \mathrm{LD}_{50}$ Units $\mathrm{ml}^{-1}$ or a $>2.5$ million fold dilution of infected brain equivalents. 


\section{Discussion}

In the years since the outbreak of BSE and the discovery of its link to $\mathrm{vCJD}^{35,40,41}$ our understanding of prion pathology and biology has increased enormously. Highly sensitive and accurate methods for the diagnostic assessment of post-mortem tissues have been developed. Application of these approaches to the diagnosis of patient biopsy samples has also proved extremely successful ${ }^{8}$. Recent reports have indicated that tissues such as blood and urine may contain levels of infectivity much higher than previously expected ${ }^{42}$. In fact, current evidence suggests that blood transfusions may provide a particularly efficient route for prion infection ${ }^{11-14}$. Taken together with data suggesting that subclinical or carrier states exist in these diseases ${ }^{43}$, transmission of vCJD via transfusion or other iatrogenic means becomes an issue of concern for public health.

Due to the prolonged pre-clinical phase of vCJD the need for a rapid, molecular diagnostic test for prion infection using easily obtainable tissues or fluids is a strategic priority for UK, European and American public health bodies. However, the strict requirements for such a test prove extremely difficult to achieve. Firstly, the quantities of $\mathrm{PrP}^{\mathrm{Sc}}$, currently our best biomarker for prion infection, are likely to be extremely low in blood, particularly in comparison to the very high levels of $\operatorname{PrP}^{\mathrm{C}}$ found in blood fractions. There is also very little information available about the biochemical nature of the infectious agent in blood. Evidence indicates that a large proportion of $\operatorname{PrP}^{\mathrm{Sc}}$ found in blood may well be protease sensitive. This means that Proteinase $\mathrm{K}$ digestion, the usual diagnostic method of distinguishing between $\operatorname{PrP}^{\mathrm{Sc}}$ and $\operatorname{PrP}^{\mathrm{C}}$, is likely to be of little use in a blood-based assay. The low abundance of the marker for prion infection and high 
background mean that any diagnostic assay will be required to be exceptionally selective as well as highly sensitive. This is underlined when considering the consequences of false positive tests. If an assay with a false positive rate of just $0.5 \%$ was to be used to screen the 2 million blood donations given annual in the United Kingdom alone, it would result in 10,000 false positive tests. This would potentially have a huge impact on healthcare as these donors would most likely require long term screening, counselling and would been seen as candidates for long term prophylactic treatments.

With these challenges in mind many novel approaches to the detection of $\mathrm{PrP}^{\mathrm{Sc}}$ in blood have been investigated including methods of amplifying the small quantities of $\operatorname{PrP}^{\mathrm{Sc}}$ present in blood fractions ${ }^{23,24}$ or from less accessible tissues such as $\operatorname{CSF}^{29}$, to increasing the sensitivity and specificity of detection methods and techniques for enriching $\mathrm{PrP}^{\mathrm{Sc}}$ from blood. However, there are problems associated with all of the current techniques under investigation. What is becoming clear is that a successful diagnostic test for preclinical prion infection is more than likely to consist of a combination of approaches.

We have used our large panel of anti-PrP monoclonal antibodies to screen for an antibody combination which can selectively distinguish prion infected brain homogenates from uninfected homogenates in a sandwich ELISA format. The ICSM10 capture and ICSM35B detection combination was shown to be capable of selectively detecting PK sensitive as well as $\mathrm{PK}$ resistant $\mathrm{PrP}^{\mathrm{Sc}}$. Optimisation of the assay allowed detection at a

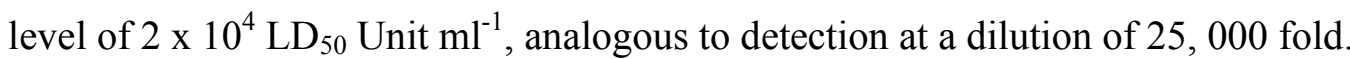


Coupling of the highly sensitive assay with the selective enrichment of $\mathrm{PrP}^{\mathrm{Sc}}$ from whole blood by immunoprecipitation with ICSM 33 (Jackson et al, Manuscript Submitted) gave an increased detection of $\operatorname{PrP}^{\mathrm{Sc}}$ at a dilution of vCJD of 150,000 fold. We also present the first report of the detection of VCJD brain homogenate spiked into a clinically relevant volume of whole blood. Our combined assay successfully detected vCJD brain homogenate spiked into $8 \mathrm{ml}$ of whole blood at a dilution of $>2.5$ million fold, equivalent to detecting $750 \mathrm{LD}_{50} \mathrm{Units}^{-1}$. Despite being short of the $10 \mathrm{LD}_{50}$ Unit $\mathrm{ml}^{-1}$ target likely to be required for detection of $\mathrm{PrP}^{\mathrm{Sc}}$ in whole blood it remains a significant improvement upon the detection limit of 50,000-fold currently available using the most sensitive methodology for detection of $\operatorname{PrP}^{\mathrm{Sc}}$ in tissues and clinical diagnosis of $\mathrm{vCJD}$ Wadsworth JD, 20018149 /id\}. 


\section{Acknowledgements}

We are grateful to Mr Ray Young for his assistance in preparation of the figures. This work was funded by the UK Medical Research Council. 


\section{Figure Legends}

Figure 1. Monoclonal antibody ICSM 10 can distinguish between uninfected and prion infected brain homogenates in the absence of PK digestion.

RML-infected and uninfected normal control CD1 brain homogenates were analysed by ICSM 10 capture and ICSM35B detection sandwich ELISA both before and after PK digestion and in a native and SDS denatured state. Effective discrimination was achieved between infected and control samples without the need for PK digestion. PK digestion reduced the observable RML signal by $58 \%$.

\section{Figure 2. Optimisation of ICSM10 capture/ICSM35B detection sandwich ELISA}

(A) Optimisation of denaturant concentration. Samples were denatured in increasing concentration of $\mathrm{GdHCl}$ before application to the ELISA. Samples were diluted to $600 \mu 1$ with IP buffer and $50 \mu 1$ aliquots analysed $(n=6)$. Optimal signal to noise ratio was achieved at an initial denaturant concentration of $4 \mathrm{M} \mathrm{GdHCl}$, with overall signal levels equivalent to that achieved with SDS denaturation. (B) Samples were denatured at 4M $\mathrm{GdHCl}$ before dilution with increasing volumes of IP buffer. $50 \mu 1$ aliquots per well were analysed ( $\mathrm{n}=6$ ). Dilution to $0.4 \mathrm{M}$ final denaturant gave the optimal signal to noise ratio and increased the positive RML signal output by 5 fold in comparison to SDS denatured antigen. Assay sensitivity was doubled by the inclusion of a Thermolysin step, from a 2,000 fold dilution of RML brain $\left(2.5 \times 10^{5} \mathrm{LD}_{50}\right.$ Units $\left.\mathrm{ml}^{-1}\right)$ before treatment (C) to a 4,000 fold dilution $\left(1.25 \times 10^{5} \mathrm{LD}_{50}\right.$ Units $\left.\mathrm{ml}^{-1}\right)$ after digestion (D) with $0.1 \mu \mathrm{g} / \mathrm{ml}$ Thermolysin at $60^{\circ} \mathrm{C}$ for 10 minutes $(n=6)$. Cut off for detection is the mean $\mathrm{CD} 1$ signal plus 3 standard deviations and is shown as a dashed, horizontal line. 
Figure 3. Sensitivity of detection of vCJD spiked into whole blood $10 \% \mathrm{w} / \mathrm{v}$ vCJD brain homogenate was serially diluted into $10 \% \mathrm{w} / \mathrm{v}$ normal brain homogenate and then $1 \mu 1$ spiked into $10 \mu$ laliquots of normal whole human blood $(n=3)$. Normal control brain homogenate was similarly diluted into $10 \mu 1$ of normal whole blood and $10 \mu \mathrm{l}$ aliquots analysed. All samples therefore contain a total of $1 \% \mathrm{w} / \mathrm{v}$ total brain homogenate. After processing, aliquots of $50 \mu \mathrm{l}$ per well were analysed on microtitre plates $(n=3)$. The equivalent of a 25,000 fold dilution of whole vCJD brain was

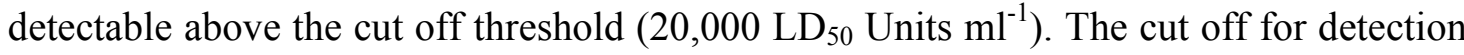
is the mean CD1 signal plus 3 standard deviations and is shown as a dashed, horizontal line.

Figure 4. Strategy for coupled immunoprecipitation and high sensitivity ELISA assay

Proposed assay for detection of $\mathrm{PrP}^{\mathrm{Sc}}$ in clinical volumes of whole blood. $\operatorname{PrP}^{\mathrm{Sc}}$ is selectively captured by ICSM 33 coated magnetic beads. The beads are washed to remove unbound $\operatorname{PrP}^{\mathrm{C}}$. Thermolysin treatment is performed while $\mathrm{PrP}^{\mathrm{Sc}}$ is still bound to the beads to further reduce background. Antigen is eluted in denaturing conditions and applied to ICSM10 coated ELISA plates for detection.

Figure 5. Immunoprecipitation and detection of vCJD spiked into whole blood (A) $10 \% \mathrm{w} / \mathrm{v}$ vCJD brain homogenate was serially diluted into $10 \% \mathrm{w} / \mathrm{v}$ normal brain homogentate then spiked into $250 \mu \mathrm{l}$ of normal whole human blood (n=3). An equivalent 
volume of normal $10 \% \mathrm{w} / \mathrm{v}$ brain homogenate was spiked into whole blood as a control. ICSM 33 immunoprecipitation and ICSM 10 capture/ICSM 35B detection ELISA indicate that the coupled assay could detect a 150,000 fold dilution of vCJD brain (threshold is average of normal background plus 3 standard deviations), equivalent to 3,200 $\mathrm{LD}_{50}$ Units $\mathrm{ml}^{-1}$. (B) Normal and vCJD 10\% w/v brain were spiked into $8 \mathrm{ml}$ of normal whole human blood $(n=3)$. Detection of $\mathrm{VCJD}$ was possible at dilution of vCJD brain of $750 \mathrm{LD}_{50}$ Units $\mathrm{ml}^{-1}$, equivalent to $\sim 15 \mathrm{pg}$ of $\operatorname{PrP}^{\mathrm{Sc}}$ (cut off threshold is the Normal mean plus 3 standard deviations). This represents detection of $\operatorname{PrP}^{\mathrm{Sc}}$ at $>2.5$ million fold dilution. 


\section{References}

1. Prusiner SB. Prions. Proc Natl Acad Sci U.S.A. 1998 Nov 10;95(23):13363-83.

2. Collinge J. Prion diseases of humans and animals: their causes and molecular basis. Annu.Rev.Neurosci. 2001;24:519-50.

3. Griffith JS. Self Replication and scrapie. Nature 1967;215:1043-4.

4. Prusiner SB. Novel proteinaceous infectious particles cause scrapie. Science 1982;216:136-44.

5. World Health Organization. The Revision of the Surveillance Case Definition for Variant Crequtzfeldt-Jakob Disease (vCJD): Report of a WHO Consultation, Edinburgh. World Health Organ Tech.Rep.Ser. 2004.

6. Wadsworth JD, Joiner S, Hill AF, Campbell TA, Desbruslais M, Luthert PJ, Collinge J. Tissue distribution of protease resistant prion protein in variant CJD using a highly sensitive immuno-blotting assay. Lancet 2001;358(9277):171-80.

7. Hill AF, Butterworth RJ, Joiner S, Jackson GS, Rossor MN, Thomas DJ, Frosh A, Tolley N, Bell JE, Spencer M, et al. Investigation of variant Creutzfeldt-Jakob disease and other human prion diseases with tonsil biopsy samples. Lancet 1999 Jan 16;353(9148):183-9.

8. Wadsworth JD, Powell C, Beck J, Joiner S, Linehan J, Brandner S, Mead S, Collinge J. Molecular diagnosis of human prion disease. In: Hill AF, editor. Prion Protein Protocols: Methods in Molecular Biology. 2008. p. 199-299.

9. Soto C. Diagnosing prion diseases: needs, challenges and hopes. Nat Rev.Microbiol. 2004 Oct;2(10):809-19.

10. Lehto MT, Peery HE, Cashman NR. Current and future molecular diagnostics for prion diseases. Expert.Rev.Mol.Diagn. 2006 Jul;6(4):597-611.

11. Houston F, McCutcheon S, Goldmann W, Chong A, Foster J, Siso S, Gonzalez L, Jeffrey M, Hunter N. Prion diseases are efficiently transmitted by blood transfusion in sheep. Blood 2008 Jul 22;112(12):4739-45.

12. Llewelyn CA, Hewitt PE, Knight RS, Amar K, Cousens S, Mackenzie J, Will RG. Possible transmission of variant Creutzfeldt-Jakob disease by blood transfusion. Lancet 2004 Feb 7;363(9407):417-21.

13. Peden AH, Head MW, Ritchie DL, Bell JE, Ironside JW. Preclinical vCJD after blood transfusion in a PRNP codon 129 heterozygous patient. Lancet 2004 Aug 7;364(9433):527-9. 
14. Wroe SJ, Pal S, Siddique D, Hyare H, Macfarlane R, Joiner S, Linehan J, Brandner $\mathrm{S}$, Wadsworth JD, Hewitt $\mathrm{P}$, et al. Clinical presentation and pre-mortem diagnosis of variant Creutzfeldt-Jakob disease associated with blood transfusion: a case report. Lancet 2006 Dec 9;368(9552):2061-7.

15. Cervenakova L, Yakovleva O, McKenzie C, Kolchinsky S, McShane L, Drohan WN, Brown P. Similar levels of infectivity in the blood of mice infected with human-derived vCJD and GSS strains of transmissible spongiform encephalopathy. Transfusion 2003 Dec;43(12):1687-94.

16. Safar J, Wille H, Itri V, Groth D, Serban H, Torchia M, Cohen FE, Prusiner SB. Eight prion strains $\mathrm{PrP}^{\mathrm{Sc}}$ molecules with different conformations. Nat.Med. 1998;4(10):1157-65.

17. Tzaban S, Friedlander G, Schonberger O, Horonchik L, Yedidia Y, Shaked G, Gabizon R, Taraboulos A. Protease-sensitive scrapie prion protein in aggregates of heterogeneous sizes. Biochemistry 2002 Oct 22;41(42):12868-75.

18. Kuczius T, Groschup MH. Differences in proteinase K resistance and neuronal deposition of abnormal prion proteins characterize bovine spongiform encephalopathy (BSE) and scrapie strains. Mol.Med. 1999 Jun;5(6):406-18.

19. Pastrana MA, Sajnani G, Onisko B, Castilla J, Morales R, Soto C, Requena JR. Isolation and Characterization of a Proteinase K-Sensitive $\operatorname{PrP}(\mathrm{Sc})$ Fraction. Biochemistry 2006 Dec 26;45(51):15710-7.

20. Thackray AM, Hopkins L, Bujdoso R. Proteinase K-sensitive disease-associated ovine prion protein revealed by conformation-dependent immunoassay. Biochem.J 2007 Jan 10;401(2):475-83.

21. Cronier S, Gros N, Tattum MH, Jackson GS, Clarke AR, Collinge J, Wadsworth JD. Detection and characterization of proteinase K-sensitive disease-related prion protein with thermolysin. Biochem J 2008 Aug 6;416(2):297-305.

22. Saborio GP, Permanne B, Soto C. Sensitive detection of pathological prion protein by cyclic amplification of protein misfolding. Nature 2001 Jun 14;411(6839):810-3.

23. Castilla J, Saa P, Soto C. Detection of prions in blood. Nat Med 2005 Sep;11(9):982-5.

24. Saa P, Castilla J, Soto C. Presymptomatic detection of prions in blood. Science 2006 Jul 7;313(5783):92-4.

25. Thorne L, Terry LA. In vitro amplification of PrPSc derived from the brain and blood of sheep infected with scrapie. J Gen Virol 2008 Dec;89(Pt 12):3177-84. 
26. Jones M, Peden A, Prowse C, Groner A, Manson J, Turner M, Ironside J, MacGregor I, Head M. In vitro amplification and detection of variant CreutzfeldtJakob disease $\operatorname{PrP}(\mathrm{Sc})$. J Pathol 2007 Jul 5.

27. Jones M, Peden AH, Yull H, Wight D, Bishop MT, Prowse CV, Turner ML, Ironside JW, MacGregor IR, Head MW. Human platelets as a substrate source for the in vitro amplification of the abnormal prion protein $(\operatorname{PrP})$ associated with variant Creutzfeldt-Jakob disease. Transfusion 2009 Feb 19.

28. Deleault NR, Harris BT, Rees JR, Supattapone S. Formation of native prions from minimal components in vitro. Proc Natl Acad Sci U S A 2007;104(23):9741-6.

29. Atarashi R, Moore RA, Sim VL, Hughson AG, Dorward DW, Onwubiko HA, Priola SA, Caughey B. Ultrasensitive detection of scrapie prion protein using seeded conversion of recombinant prion protein. Nat Methods 2007 Aug;4(8):64550.

30. Bellon A, Seyfert-Brandt W, Lang W, Baron H, Groner A, Vey M. Improved conformation-dependent immunoassay: suitability for human prion detection with enhanced sensitivity. J Gen.Virol. 2003 Jul;84(Pt 7):1921-5.

31. Kim JI, Wang C, Kuizon S, Xu J, Barengolts D, Gray PC, Rubenstein R. Simple and specific detection of abnormal prion protein by a magnetic bead-based immunoassay coupled with laser-induced fluorescence spectrofluorometry. J Neuroimmunol. 2005 Jan;158(1-2):112-9.

32. Birkmann E, Henke F, Weinmann N, Dumpitak C, Groschup M, Funke A, Willbold D, Riesner D. Counting of single prion particles bound to a capture-antibody surface (surface-FIDA). Vet.Microbiol 2007 Apr 7;123(4):294-304.

33. Pan T, Chang B, Wong P, Li C, Li R, Kang SC, Robinson JD, Thompsett AR, Tein $\mathrm{P}$, Yin S, et al. An Aggregation-Specific Enzyme-Linked Immunosorbent Assay: Detection of Conformational Differences between Recombinant PrP Protein Dimers and PrPSc Aggregates. J Virol 2005 Oct;79(19):12355-64.

34. Khalili-Shirazi A, Summers L, Linehan J, Mallinson G, Anstee D, Hawke S, Jackson GS, Collinge J. PrP glycoforms are associated in a strain-specific ratio in native PrPSc. J.Gen.Virol. 2005 Sep;86(9):2635-44.

35. Collinge J, Sidle KCL, Meads J, Ironside J, Hill AF. Molecular analysis of prion strain variation and the aetiology of 'new variant' CJD. Nature 1996;383:685-90.

36. Chandler RL. Encephalopathy in mice produced by inoculation with scrapie brain material. Lancet 1961;1:1378-9.

37. Pan KM, Stahl N, Prusiner SB. Purification and properties of the cellular prion protein from Syrian hamster brain. Protein Sci. 1992;1:1343-52. 
38. Owen JP, Maddison BC, Whitelam GC, Gough KC. Use of thermolysin in the diagnosis of prion diseases. Mol Biotechnol. 2007 Feb;35(2):161-70.

39. Brown P, Rohwer RG, Dunstan BC, MacAuley C, Gajdusek DC, Drohan WN. The distribution of infectivity in blood components and plasma derivatives in experimental models of transmissible spongiform encephalopathy. Transfusion 1998 Sep;38(9):810-6.

40. Bruce ME, Will RG, Ironside JW, McConnell I, Drummond D, Suttie A, McCardle L, Chree A, Hope J, Birkett C, et al. Transmissions to mice indicate that 'new variant' CJD is caused by the BSE agent. Nature 1997;389:498-501.

41. Hill AF, Desbruslais M, Joiner S, Sidle KC, Gowland I, Collinge J, Doey LJ, Lantos P. The same prion strain causes vCJD and BSE. Nature 1997 Oct 2;389(6650):448-50, 526.

42. Gonzalez-Romero D, Barria MA, Leon P, Morales R, Soto C. Detection of infectious prions in urine. FEBS Lett 2008 Aug 13.

43. Hill AF, Joiner S, Linehan J, Desbruslais M, Lantos PL, Collinge J. Species barrier independent prion replication in apparently resistant species. Proc Natl Acad Sci USA 2000;97(18):10248-53. 
Figures

Fig 1

Figure 1

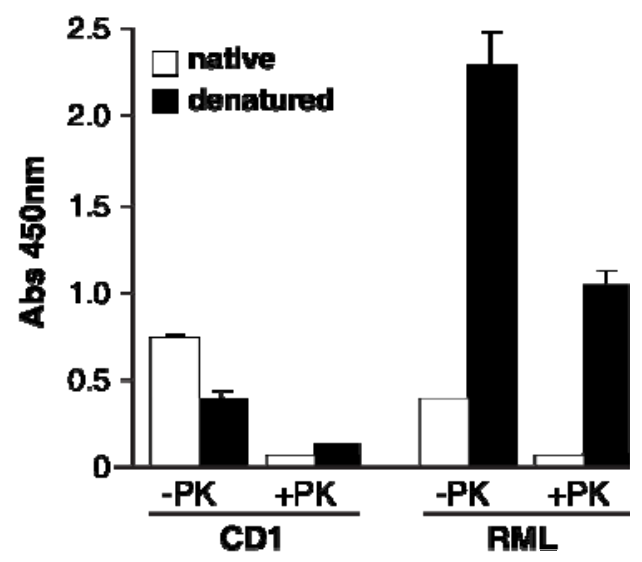


Fig 2

Figure 2
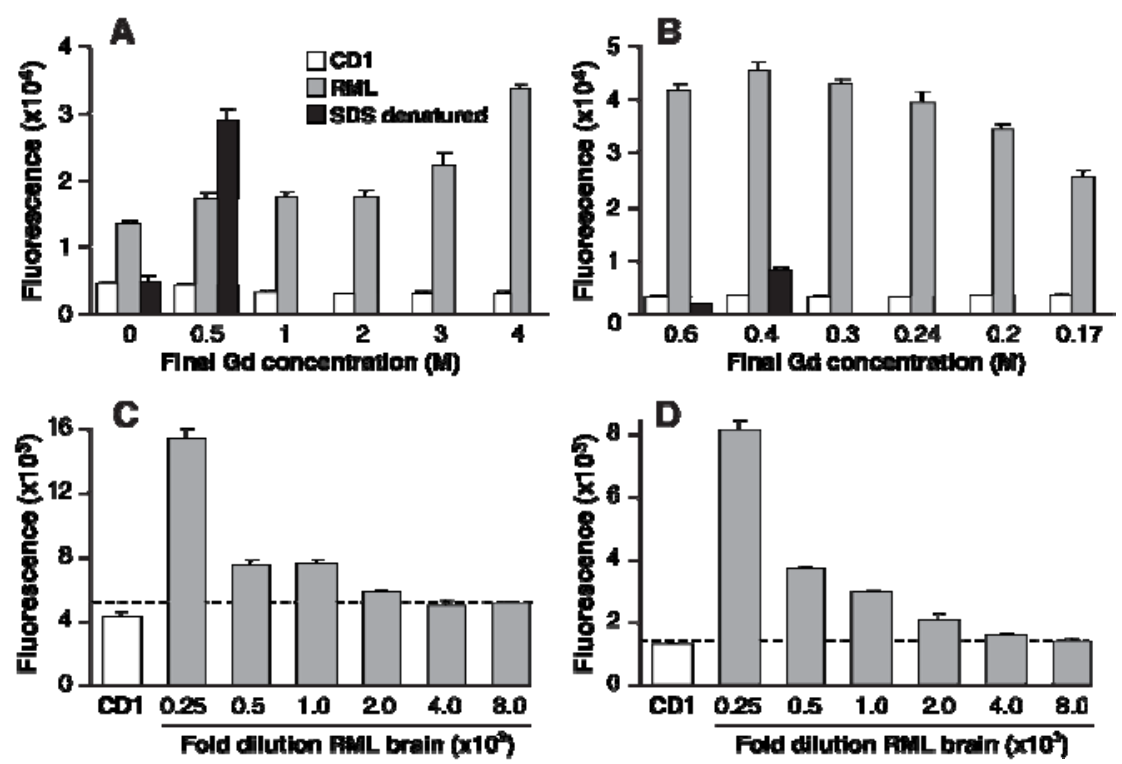
Fig 3

Figure 3

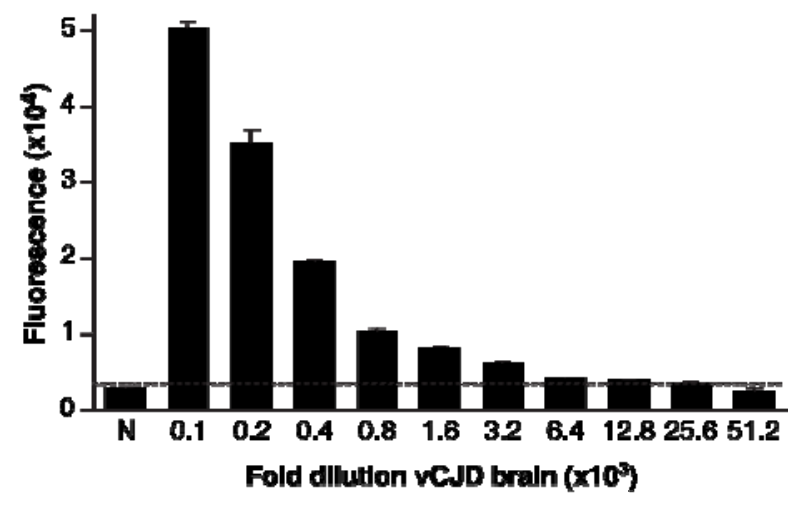


Fig 4

Figure 4

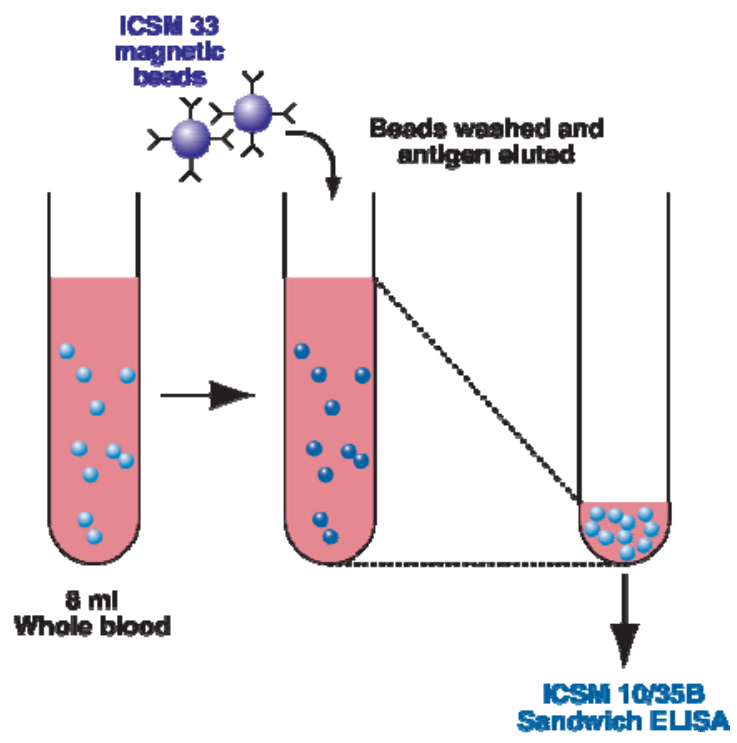


Fig 5

Figure 5
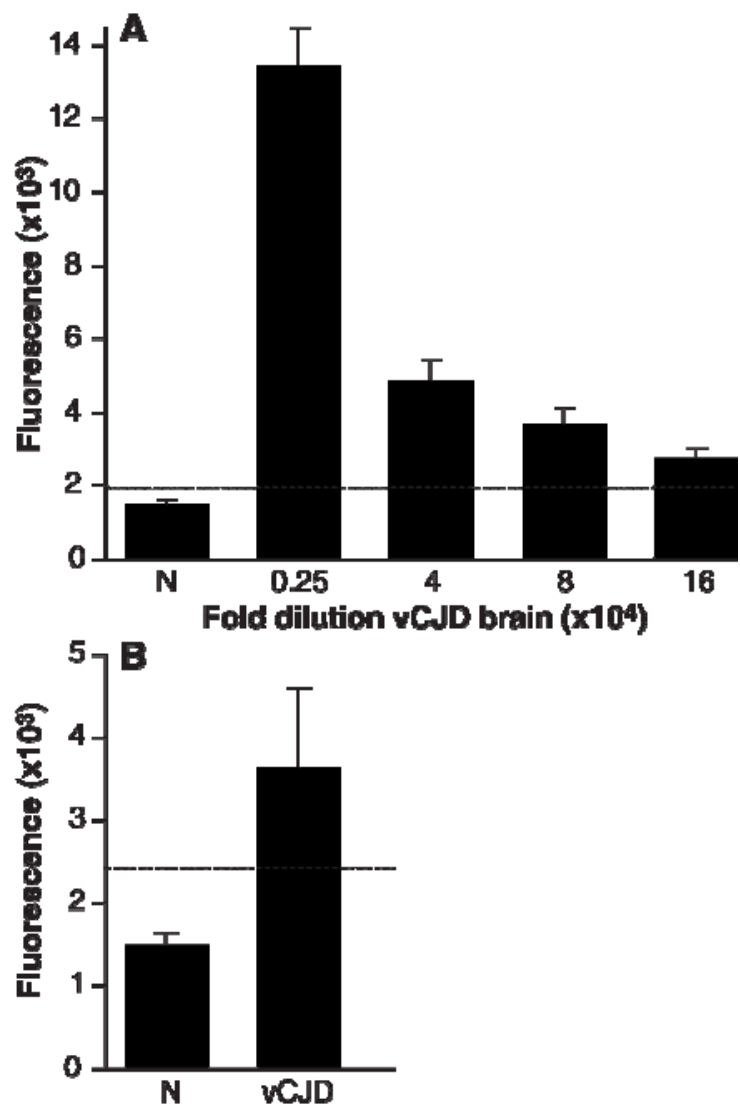

Brain homogenate spiked Into whole blood 